\title{
Study of Simulation and Experimental Effect of Vaccum Degrees Between Glass Containers and Absorber on Solar Water Heater with Absorber Sinusoidal Type
}

\author{
Royyan Firdaus ${ }^{1}$, Djatmiko Ichsani ${ }^{1}$, Mohamad Hakam ${ }^{1}$, and A'rasy Fahruddin ${ }^{1}$
}

\begin{abstract}
In this era, the energy crisis is the spotlight, as many of us rely heavily on non-renewable energy such as fuel oil and natural gas, so that if the fuel source runs out, then all life processes will also stop. Not only that, the pollution caused by the use of fuel oil is very bad for the environment. Therefore, there is need for savings in all aspects of life that require energy. One of them is solar energy. In this research we are researching how to analyze and make solar water heater experiments effective and efficient so that can be widely used by many people. Solar water heater is very varied in terms of methods used to take the sun's heat. It all depends on the design and analysis made. In this case the wide absorption of solar thermal energy absorbed by the absorber is also very important, for that we use sinusoidal-shaped absorber plate. Furthermore, through the journals that ever existed, the researchers took 2 important aspects that need to be in the study that is with the variation of vacuum and discharge rates with the thickness of the sinusoidal (ס) $2 \mathrm{~mm}$ absorber plate. For the vacuum level will be varied 0 $\mathrm{mm} . \mathrm{Hg},-20 \mathrm{~mm} . \mathrm{Hg},-40 \mathrm{~mm} . \mathrm{Hg},-60 \mathrm{~mm} . \mathrm{Hg},-80 \mathrm{~mm} . \mathrm{Hg},-100$ $\mathrm{mm} . \mathrm{Hg},-120 \mathrm{~mm} . \mathrm{Hg}$ and by varying the fluid flow of work by adjusting the valve opening, that is from $18 \mathrm{~L}$ /hour to $22 \mathrm{~L} / \mathrm{hour}$ with increase of $2 \mathrm{~L} / \mathrm{hour}$. By varying the level of vacuum between the absorber plate and the cover glass, it is expected to minimize the loss coefficient, increase the temperature of the absorber, and the temperature of the cover glass down. So it can improve collector efficiency 63.29\%. and usefull Heat 760.39 Watt/m2, when the solar collector is set at a discharge of 22 L/hour, vacuum level -120 mmHg.
\end{abstract}

Keywords-Solar Collector, Alternative Energy, Sinusoidal Absorber, Solar Energy, The Collector Efficiency.

\section{INTRODUCTION}

The study of the performance of solar collectors as water heaters has been widely practiced. Solar water heater collectors have a wide variety of variations. One of the variations is the absorber of the solar collector. The flat plate with tube solar collector has been extensively researched by modifying the position of the pipe against the flat plate. Flat solar plate collectors are widely produced in bulk as a solar water heater. In flat plate solar collectors it needs welding to connect pipes and plates. The connection

\footnotetext{
${ }^{1}$ Royyan Firdaus, Djatmiko Ichsani, Mohamad Hakam, and A'rasy Fahruddin are with Department of Mechanical Engineering, Institut Teknologi Sepuluh Nopember, Surabaya, 60111, Indonesia. E-mail: djatmiko@me.its.ac.id.
}

creates a thermal resistance that will inhibit heat transfer from the absorber plate to the pipe.

The use of wave absorber plates on solar water heater collectors is expected to overcome the weaknesses in the flat plate collector with the tube. In this solar collector the solar radiation absorbed by the absorber plate will be directly transferred to the water. In addition to the same collector dimensions, the wave absorber plate has a greater heat absorption area. The use of the wave plate as an absorber plate can increase absorbsivity because in addition to receiving direct solar radiation, it also receives reflections from adjacent wave plates. Thus it is expected that the absorber plate has a good performance and deserves to be used as an absorber plate for water heaters.

The heat loss through the top of the solar collector is part of the largest heat loss. By reducing heat loss from the top of the collector will increase collector efficiency. For that we need to research how to reduce the heat loss.

In this study we used a simulation approach to predict the best design for a solar water heater. So get the efficiency and maximum performance.

\section{A. Analisys of Heat Transfer and Thermal Performanced}

Radiation heat transfer is the transfer of heat energy with the help of electromagnetic waves. Radiation heat transfer is different from convection and conduction heat transfer. Radiation does not require an intermediary, even radiation occurs more effectively in vacuum. The radiation emitted by the surface of a substance comes from the heat energy of the substance being displaced by the surface. The magnitude of the radiation heat transfer rate is strongly influenced by the ability of a surface to emit energy $(\varepsilon)$ and temperature difference $(\Delta \mathrm{T})$. The rate of radiation heat transfer can be seen in the following equation:

$$
\begin{aligned}
& q_{\text {rad }}^{\prime \prime}=\sigma \cdot \varepsilon\left(T_{s}^{4}-T_{\text {sur }}^{4}\right) \\
& Q_{\text {rad }}^{\prime \prime}=\frac{\sigma}{\frac{1}{\varepsilon_{1}}+\frac{1}{\varepsilon_{2}}-1}\left(T_{1}{ }^{4}-T_{\text {sur }}^{4}\right)
\end{aligned}
$$

The sun is the source of energy for life on earth. The energy that the sun has is called solar energy and radiated to reach the earth. The sun emits an average radiative energy of Gsc $=1353 \mathrm{~W} / \mathrm{m} 2$ at any time. The sun radiation that has come to earth consists of direct radiation (beam Ib) and scattering radiation (diffuse Id), as well as 
the reflection radiation from the surroundings. Solar radiation outside the atmosphere (extraterrestrial) in the horizontal plane per hour, is shown in the following expression

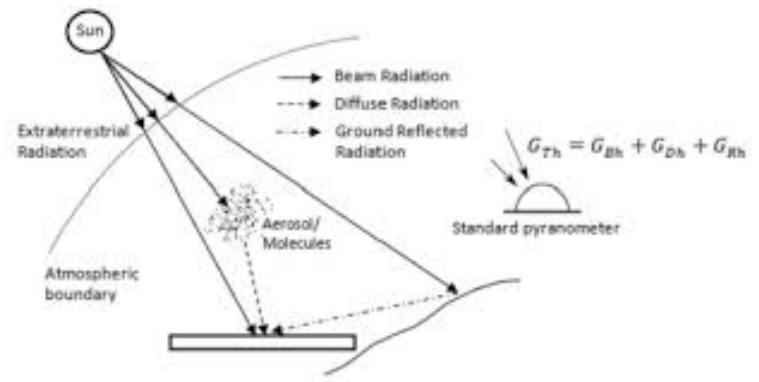

Figure 1. Intensitas beam, diffuse, dan reflected radiation

The ratio of the intensity of environmental radiation (IT) and the intensity of solar radiation in the extraterrestrial is called an hourly clearness index kT. according to the equation.

$$
k_{T}=\frac{I_{d}}{I_{o}}
$$

To know the intensity of beam and intensity diffuse, can use the following equation:

$$
\frac{I_{d}}{I_{o}}= \begin{cases}1,0-0,09 \mathrm{k}_{\mathrm{T}} & \text { for } \mathrm{k}_{\mathrm{T}} \leq 0,22 \\ 0,9511-0,1604 \mathrm{k}_{\mathrm{T}}+4,388 \mathrm{k}_{\mathrm{T}}^{2}-16,638 \mathrm{k}_{\mathrm{T}}^{3}+12,336 \mathrm{k}_{\mathrm{T}}^{4} & \text { For } 0,22 \leq \mathrm{k}_{\mathrm{T}} \leq 0,8 \\ 0,165 & \text { for } \mathrm{k}_{\mathrm{T}}>0,8\end{cases}
$$

\section{B. Radiation absorbed}

When solar radiation concerns the absorber plate of the wave then the absorbed radiation (S) will vary along the $x$ axis. the amount of radiation absorbed is as follows:

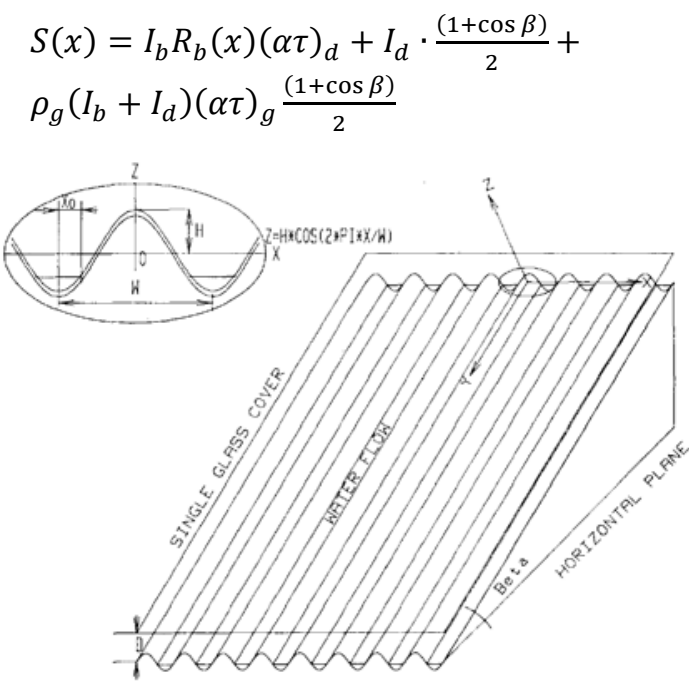

Figure. 2 Absorber sinusoidal

\section{Analysis of Solar Beam}

The use of a vector unit is appropriate for defining Figure 2 for calculating the incident angle of solar radiation on the absorber. The components of the vector unit characteristics are as follows:

$$
\begin{aligned}
\tan \alpha= & \frac{d z}{d x}=-22 \pi x \cdot \sin \left(2 \pi x^{*}\right) \\
\cos \alpha & =\frac{1}{\sqrt{1-4 \pi^{2} \phi^{2} \sin ^{2}\left(2 \pi x^{*}\right)}} \\
\sin \alpha= & \frac{\frac{d z}{d x}=-22 \pi x \cdot \sin \left(2 \pi x^{*}\right)}{\sqrt{1-4 \pi^{2} \phi^{2} \sin ^{2}\left(2 \pi x^{*}\right)}} \\
& x^{*}=\frac{x}{w^{\prime}} \quad \phi=\frac{H}{W} \\
\alpha \cdot \sin \beta & \cdot \cos \gamma-\sin \alpha \cdot \sin \gamma) i \\
& -(\cos \alpha \cdot \sin \beta \cdot \sin \gamma-\sin \alpha \cdot \sin \gamma) j \\
& +(\cos \beta \cdot \cos \alpha) k
\end{aligned}
$$$$
U=(\cos \alpha \cdot \sin \beta \cdot \cos \gamma-\sin \alpha \cdot \sin \gamma) i
$$

\section{Analysis of Heat Transfer Between Air and Cover}

Convection

$$
\begin{gathered}
\operatorname{Re}_{\mathrm{L}}=\frac{\rho v L}{\mu} \\
G r_{L}=\frac{g \cdot \beta^{\prime} \Delta T \cdot L^{3}}{v}
\end{gathered}
$$

Turbulent flow at flat plate

$$
\mathrm{Nu}_{\mathrm{L}}=0,453 \cdot \mathrm{Re}_{\mathrm{L}}^{1 / 2} \cdot \operatorname{Pr}^{1 / 3}
$$

Laminar flow flat plate $(\operatorname{ReL} \leq 5 \times 105)$

$$
\mathrm{Nu}_{L}=0,038 \cdot \mathrm{Re}_{L}^{4 / 5} \cdot \operatorname{Pr}^{1 / 3}
$$

Radiation

$$
h_{r, c-a}=\frac{\sigma \cdot \varepsilon_{c}\left(T_{c}^{4}+T_{s k y}^{4}\right)}{\left(T_{c}+T_{s k y}\right)}
$$

Thermal Heat Loss Coefficient (UL)

$$
\begin{aligned}
U_{T} & =U_{t}+U_{b} \\
U_{t} & =\frac{1}{\left(R_{1}+R_{2}\right)} \\
R_{1}^{\prime \prime} & =\frac{1}{h_{c-a}}+\frac{1}{h_{r, c-a}} \\
R_{2}^{\prime \prime} & =\frac{1}{h_{p-c}}+\frac{1}{h_{r, p-c}} \\
U_{b} & =\frac{1}{\left[\frac{L_{z}}{k_{z}}+\frac{L_{w}}{k_{w}}+\frac{2}{h_{f}}\right]} m=\sqrt{\frac{U_{L}}{k \cdot \delta}} \\
F & =\frac{\tanh \left(\frac{m(W-D)}{2}\right)}{\left(\frac{m(W-D)}{2}\right)}
\end{aligned}
$$




$$
\begin{array}{ll}
F^{\prime}=\frac{1 / U_{L}}{w\left[\frac{1}{U_{L}[D+(w-D) F]}\right]+\frac{1}{\pi \cdot D \cdot h_{f . i}}} & \begin{array}{c}
Q_{u, \text { aktual }} \\
\eta=\frac{Q_{u}}{A_{c} I_{T}}
\end{array} \cdot c_{p} \cdot\left(T_{f, \text { out }}-T_{f, \text { in }}\right) \\
F^{\prime \prime}=\frac{F_{R}}{F^{\prime}}=\frac{m \cdot c_{p}}{A_{c} \cdot U_{L} \cdot F^{\prime}}\left[1-\exp \left(-\frac{A_{c} \cdot U_{L} \cdot F^{\prime}}{c_{p}}\right)\right] & \\
F_{R}=F^{\prime} \cdot F^{\prime \prime} &
\end{array}
$$

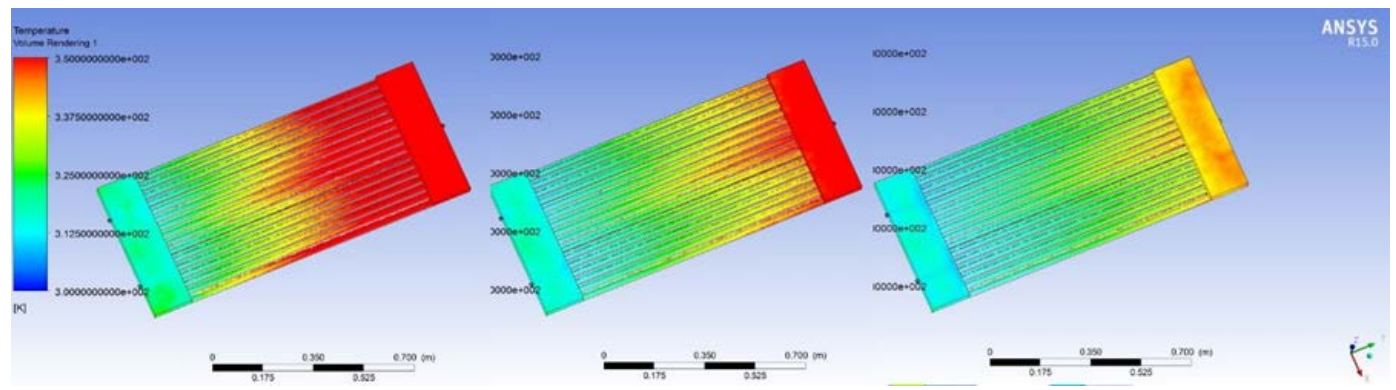

Figure 3. Result of Simulation.

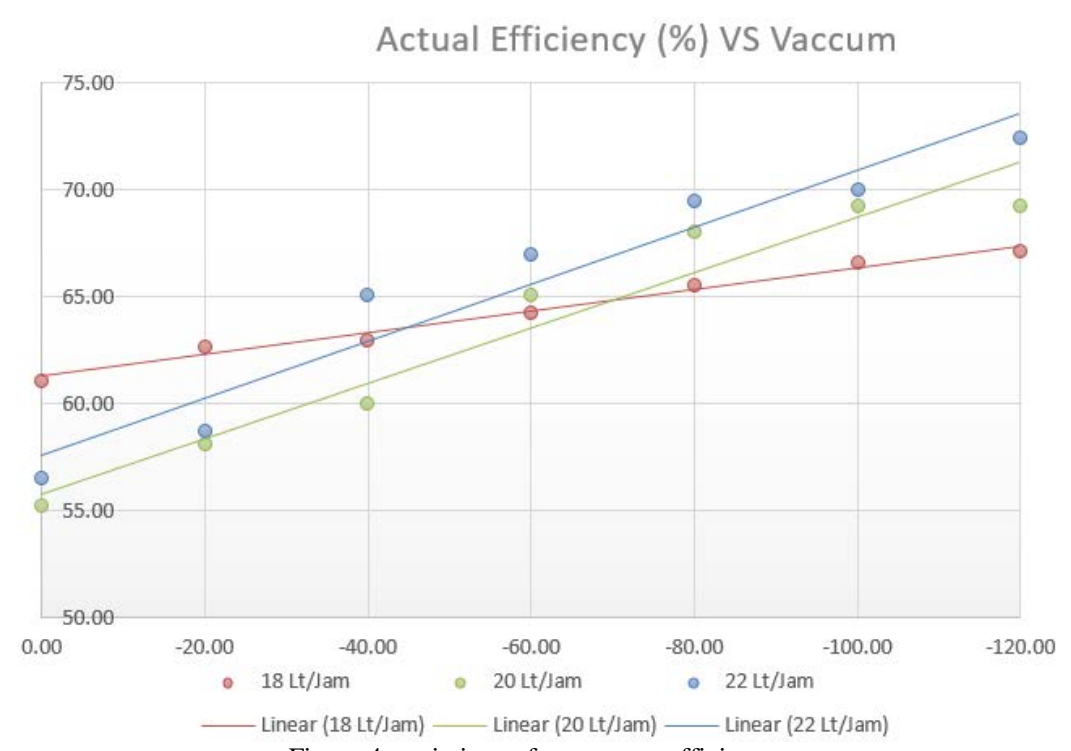

Figure 4. variations of vaccum vs efficiency

In Figure 3 is the result of simulation through solar collector. Testing is done by using variable discharge with solar radiation. From the distribution can be seen the temperature distribution shows the trend the greater the discharge the resulting temperature the lower.

In figure 4 it can be seen that when the solar collector is varied at a varied level of $0 \mathrm{mmHg},-20 \mathrm{mmHg},-40 \mathrm{mmHg}$, $-60 \mathrm{mmHg},-80 \mathrm{mmHg},-100 \mathrm{mmHg},-120$. For variation of fluid discharge from discharge of $18 \mathrm{~L}$ / hour to $22 \mathrm{~L}$ / hour with increase of $2 \mathrm{~L}$ / hour, so we get the greatest efficiency when varied to fluid discharge obtained when discharge at $22 \mathrm{~L} /$ hour and vacuum -120 mmHg.

\section{CONCLUSION}

From the experiments conducted and discussion of the data obtained, the following conclusions can be drawn:
1. With the vacum level of vacuum in the cavity between the absorber plate with cover, the resulting Qu will get bigger. It also leads to greater efficiency.

2. The larger the flow of fluid flowing under the absorber plate, the resulting Qu will be larger. It also causes the efficiency to be gained also greater.

3. The greatest efficiency occurs when the solar collector is set at a discharge of $22 \mathrm{~L} /$ hour, vacuum level -120 $\mathrm{mmHg}$, when the sun intensity is 760.39 Watt $/ \mathrm{m}^{2}$ with an efficiency of $63.29 \%$.

\section{REFERENCES}

Use the "Insert Citation" button to add citations to this document. 